\title{
Daily home fortification with iron as ferrous fumarate versus NaFeEDTA: a randomised, placebo-controlled, non-inferiority trial in Kenyan children
}

Emily M. Teshome ${ }^{1,2^{*}}$, Pauline E. A. Andang' $0^{3}$, Victor Osoti ${ }^{4}$, Sofie R. Terwel ${ }^{5}$, Walter Otieno ${ }^{6}$, Ayşe Y. Demir ${ }^{7}$, Andrew M. Prentice ${ }^{1,2}$ and Hans Verhoef ${ }^{1,2,5}$

\begin{abstract}
Background: We aimed to show the non-inferiority of home fortification with a daily dose of $3 \mathrm{mg}$ iron in the form of iron as ferric sodium ethylenediaminetetraacetate (NaFeEDTA) compared with $12.5 \mathrm{mg}$ iron as encapsulated ferrous fumarate in Kenyan children aged 12-36 months. In addition, we updated a recent meta-analysis to assess the efficacy of home fortification with iron-containing powders, with a view to examining diversity in trial results.

Methods: We gave chemoprevention by dihydroartemisinin-piperaquine, albendazole and praziquantel to 338 afebrile children with haemoglobin concentration $\geq 70 \mathrm{~g} / \mathrm{L}$. We randomly allocated them to daily home fortification for 30 days with either placebo, $3 \mathrm{mg}$ iron as NaFeEDTA or $12.5 \mathrm{mg}$ iron as encapsulated ferrous fumarate. We assessed haemoglobin concentration (primary outcome), plasma iron markers, plasma inflammation markers and Plasmodium infection in samples collected at baseline and after 30 days of intervention. We conducted a meta-analysis of randomised controlled trials in pre-school children to assess the effect of home fortification with iron-containing powders on anaemia and haemoglobin concentration at end of intervention.

Results: A total of 315 children completed the 30-day intervention period. At baseline, $66.9 \%$ of children had inflammation (plasma C-reactive protein concentration $>5 \mathrm{mg} / \mathrm{L}$ or plasma $a_{1}$-acid glycoprotein concentration $>1.0 \mathrm{~g} / \mathrm{L}$ ); in those without inflammation, $42.5 \%$ were iron deficient. There was no evidence, either in per protocol analysis or intention-to-treat analysis, that home fortification with either of the iron interventions improved haemoglobin concentration, plasma ferritin concentration, plasma transferrin receptor concentration or erythrocyte zinc protoporphyrin-haem ratio. We also found no evidence of effect modification by iron status, anaemia status and inflammation status at baseline. In the meta-analysis, the effect on haemoglobin concentration was highly heterogeneous between trials ( $I^{2}: 84.1 \%$; $p$ value for test of heterogeneity: $\left.<0.0001\right)$.

Conclusions: In this population, home fortification with either $3 \mathrm{mg}$ iron as NaFeEDTA or $12.5 \mathrm{mg}$ iron as encapsulated ferrous fumarate was insufficiently efficacious to assess non-inferiority of $3 \mathrm{mg}$ iron as NaFeEDTA compared to $12.5 \mathrm{mg}$ iron as encapsulated ferrous fumarate. Our finding of heterogeneity between trial results should stimulate subgroup analysis or meta-regression to identify population-specific factors that determine efficacy.
\end{abstract}

Trial Registration: The trial was registered with ClinicalTrials.gov (NCT02073149) on 25 February 2014.

Keywords: Anaemia, Child, Pre-school, Ferric sodium EDTA, Home fortification, Iron, Non-inferiority, Meta-analysis

\footnotetext{
* Correspondence:

Emily.teshome@lshtm.ac.uk; emily_mwadimew@yahoo.com

${ }^{1}$ MRCG Keneba at MRC Unit, Banjul, The Gambia

${ }^{2}$ MRC International Nutrition Group, Faculty of Epidemiology and Population

Heath, London School of Hygiene and Tropical Medicine, Keppel Street,

London WC1E 7HT, England, UK

Full list of author information is available at the end of the article
} International License (http://creativecommons.org/licenses/by/4.0/), which permits unrestricted use, distribution, and reproduction in any medium, provided you give appropriate credit to the original author(s) and the source, provide a link to the Creative Commons license, and indicate if changes were made. The Creative Commons Public Domain Dedication waiver (http://creativecommons.org/publicdomain/zero/1.0/) applies to the data made available in this article, unless otherwise stated. 


\section{Background}

In 2011, the World Health Organisation (WHO) recommended daily home fortification with iron $(12.5 \mathrm{mg}$ as a ferrous salt) in populations where the prevalence of anaemia in children younger than 5 years of age is $\geq 20 \%$ [1], which covers most developing countries [2]. This recommendation was based on a meta-analysis of randomised controlled trials showing moderate quality evidence for an effect on anaemia and haemoglobin concentration [3].

The WHO-recommended dose of $12.5 \mathrm{mg}$ iron was established to meet almost $90 \%$ of the estimated total iron requirement of children aged 6-18 months [4]. Several trials have shown, however, that supplementation or food fortification with iron at this dose can increase rates of hospital admissions [5] as well as diarrheal and respiratory diseases [6]. In addition, it can produce a potentially more pathogenic gut microbiota profile that is associated with gut inflammation [7, 8]. Ingestion of ferrous salts also frequently causes mild gastrointestinal adverse effects (e.g. constipation, nausea, vomiting and epigastric discomfort) that may reduce adherence to treatment [9]. The frequency and severity of such effects depend on dose and dosage schedule [10, 11], may be due to oxidative stress [12] and appear to be reduced when iron is taken with food.

By comparison, ingestion of a low dose of highly bioavailable iron (3 mg iron as ferric sodium ethylenediaminetetraacetate (NaFeEDTA)) may result in similar or even higher quantities of absorbed iron [13] and may be non-inferior in its effect on iron status. It may have the advantage that reduced amounts of ingested iron may reduce proliferation of pathogenic gut bacteria, produce less oxidative stress and increase tolerability and adherence [14]. In addition, iron as NaFeEDTA has been reported to cause less oxidative stress than an equimolar dose of iron as ferrous sulphate [15]. No study has so far compared the efficacy of daily home iron fortification with $12.5 \mathrm{mg}$ iron as encapsulated ferrous fumarate versus $3 \mathrm{mg}$ iron as NaFeEDTA.

In malaria-endemic areas, WHO has recommended that iron interventions should be implemented in conjunction with measures to control malaria [1], because there is substantial evidence that iron interventions can increase malaria rates in young children [16].

We aimed to show non-inferiority of home fortification with $3 \mathrm{mg}$ iron as NaFeEDTA compared with $12.5 \mathrm{mg}$ iron as encapsulated ferrous fumarate in children aged 12-36 months under cover of chemoprevention against malaria. We conducted a pre-specified analysis to explore to what extent efficacy depended on baseline iron markers (haemoglobin concentration, plasma concentrations of ferritin and soluble transferrin receptor measured), because iron absorption is known to depend on iron status.
Lastly, we used results from our present study and other recent reports to update the meta-analysis by Salam et al. [5], with a view to examining diversity in study results.

\section{Methods}

Details of study methods are described in the statistical analysis plan (Additional file 1). During study implementation, there were no major amendments to the protocol.

\section{Study setting and subjects}

Fieldwork was conducted between January 2014 and December 2014 in Kisumu West District, Kenya. Malaria is highly endemic in the area $[17,18]$, with virtually all infections due to Plasmodium falciparum. In children aged 1-4 years, the prevalence of infections due to $P$. falciparum has been reported to range between 39\% and 63\% [19]. Previous trials in the area have shown that iron supplementation resulted in increased haemoglobin concentrations among pre-school children, suggesting that iron deficiency is common [20-22].

\section{Study design}

This was a randomised, double-blind, non-inferiority trial with three arms: $3 \mathrm{mg}$ iron as NaFeEDTA (experimental treatment); $12.5 \mathrm{mg}$ iron as encapsulated ferrous fumarate (active control treatment); and placebo. We included the placebo arm to demonstrate superiority of the investigational drug over placebo (proof of efficacy) [23]. The study was conceived as an explanatory trial to evaluate efficacy with maximal compliance.

\section{Data collection timelines and field procedures}

Community health workers invited parents of children aged 12-36 months old for screening at the research clinic. During screening, research assistants measured height and length within $0.1 \mathrm{~cm}$ using wooden measuring boards (UNICEF, Copenhagen, Denmark) and weight to the nearest $100 \mathrm{~g}$ using a Salter scale (UNICEF, Copenhagen, Denmark). They also administered a standardised form to collect vital data and household characteristics data. Medical staff conducted a medical examination and collected venous blood $(4 \mathrm{~mL})$ in tubes containing Li-heparin for subsequent determination of iron biomarkers and Plasmodium infection. Children who attained the eligibility criteria were given premedications 3 days before randomisation to treatment allocation.

\section{Pre-medications}

Medical staff administered drugs to prevent malaria and to control anaemia due to helminth infections in the subsequent intervention period. These pre-medications 
comprised: (1) dihydroartemisinin-piperaquine (SigmaTau, Rome, Italy; tablets of $40 \mathrm{mg}$ of dihydroartemisinin and $320 \mathrm{mg}$ of piperaquine), for 3 days at a daily target dose of $4 \mathrm{mg} / \mathrm{kg}$ body weight [24]; (2) albendazole (Indoco Remedies, Mumbai, India), for 3 days at a daily target dose of $200 \mathrm{mg}$ or $400 \mathrm{mg}$ for children aged 12-24 months and $>24$ to 36 months, respectively; (3) praziquantel (Cosmos, Nairobi, Kenya; 600-mg tablets), as a single dose at a target dose of $40 \mathrm{mg} / \mathrm{kg}$ body weight [25]. Piperaquine is eliminated slowly (mean elimination half-life: 23 days in children in Burkina Faso) [26], resulting in a protective efficacy against malaria for at least 1 month [27, 28]. Medical staff observed that the child swallowed the first dose of the premedication drugs at the research clinic. Parents were instructed to administer the remaining two doses of dihydroartemisinin-piperaquine and albendazole at home on the subsequent 2 days.

\section{Eligibility}

Children were eligible for enrolment in the study after attaining the following eligibility criteria: aged 12-36 months; the child was expected to remain resident in the study area for the duration of the intervention and follow-up; no known or reported allergy to premedication drugs; not severely malnourished (weightfor-height $\mathrm{z}$-score $<-3 \mathrm{SD}$ ); absence of fever (axillary temperature $<37.5^{\circ} \mathrm{C}$ ); absence of reported or suspected systemic disorders (e.g. HIV infection, tuberculosis, sickle cell disease); haemoglobin concentration $\geq 70 \mathrm{~g} / \mathrm{L}$; and at least one parent signed an informed consent form. Of the 433 children screened between April and July 2014, 338 children were randomised for intervention. In our sample size calculations [29-31], we specified a non-inferiority margin for haemoglobin concentration of $4.7 \mathrm{~g} / \mathrm{L}$, which we expected to preserve $50 \%$ of the reported and anticipated minimum effect of $12.5 \mathrm{mg}$ ferrous fumarate (9.3 g/L, [32]; Additional file 1).

\section{Randomisation}

Three days after the screening visit, children who met the eligibility criteria were randomised at the research clinic. We used a stratified block design to achieve group balance in size and baseline haemoglobin concentration. A person not involved in the fieldwork assigned the three treatment groups to a sequence of random permuted blocks of sizes 6 or 9 nested within two strata defined by baseline haemoglobin concentration class $(<100 \mathrm{~g} / \mathrm{L}$ and $\geq 100 \mathrm{~g} / \mathrm{L})$, using tables with random numbers and random permuted blocks. Following this scheme, two other persons not involved in the fieldwork produced a set of labels with a child's identification number that included a letter for stratum (A or B) and a consecutive allocation number as indicated by the randomisation scheme. At the randomisation visit, the trial coordinator assigned children successively to the next available allocation number randomised for treatment and according to appropriate stratum.

\section{Composition of fortificants}

We used three types of micronutrient powders that contained vitamin A and zinc contents as per WHO recommendations [1], 11 other micronutrients (Table 1) at doses as recommended by the Home Fortification Technical Advisory Group [33] and, in addition, either $3 \mathrm{mg}$ iron as NaFeEDTA, or $12.5 \mathrm{mg}$ iron as encapsulated ferrous fumarate, or no iron (placebo). The micronutrient powders were packed in 1-g plain white foil single-serve sachets that were identical in appearance and that did not result in apparent differences in taste, texture or colour of $u j i$ (porridge made of maize flour). We excluded folic acid because of concerns that it may cause failure of antifolate drugs and because of the absence of evidence that folate deficiency anaemia is a public health problem among children in developing countries [34].

\section{Blinding}

Researchers, outcome assessors and parents remained blinded to the type of treatment allocated to each child until the 30-day intervention period had been completed. At this point they were partially unblinded to know if the child was in the placebo or iron group.

Table 1 Composition of home fortificants

\begin{tabular}{ll}
\hline Micronutrient & Content \\
\hline Vitamin A & $300 \mu \mathrm{g} \mathrm{RE}$ \\
Vitamin D & $5 \mu \mathrm{g}$ \\
Vitamin E & $5 \mathrm{mg}$ \\
Vitamin C & $30 \mathrm{mg}$ \\
Thiamin (vitamin $\mathrm{B}_{1}$ ) & $0.5 \mathrm{mg}$ \\
Riboflavin (vitamin $\mathrm{B}_{2}$ ) & $0.5 \mathrm{mg}$ \\
Niacin (vitamin $\mathrm{B}_{3}$ ) & $6 \mathrm{mg}$ \\
Vitamin $\mathrm{B}_{6}$ (pyridoxine) & $0.5 \mathrm{mg}$ \\
Vitamin $\mathrm{B}_{12}$ (cobalamin) & $0.9 \mu \mathrm{g}$ \\
Iron & \\
ElTHER iron as encapsulated ferrous fumarate & $12.5 \mathrm{mg}$ \\
OR iron as NaFeEDTA & $3 \mathrm{mg}$ \\
OR no iron (placebo) & $0 \mathrm{mg}$ \\
Zinc & $5 \mathrm{mg}$ \\
Copper & $0.56 \mathrm{mg}$ \\
Selenium & $17 \mu \mathrm{g}$ \\
lodine & $90 \mu \mathrm{g}$ \\
\hline RE retino &
\end{tabular}

$R E$ retinol equivalents 
Investigators were fully unblinded after the fieldwork was complete and the statistical analysis plan written.

\section{Adherence monitoring}

Adherence to intervention was monitored using an electronic monitoring and time-recording device (Medication Events Monitoring Systems, MEMS, 6 TrackCap $45 \mathrm{~mm}$ without LCD display; WestRock, Sion, Switzerland; http://www.medamigo.com/) that is considered to be the reference standard and superior to medication counts and self-reported adherence methods [35, 36]. The batteryoperated device consists of a cap with a built-in microprocessor that fits the bottle with the micronutrient sachets. It records and internally stores dates and times of all openings. Parents were taught how to use the bottle with the electronic device without knowing that the device was monitoring the openings of the bottle and instructed to return the electronic device with any remaining sachets at the end of 30 days of intervention.

\section{Intervention period}

On the first day of intervention, research assistants gave parents a supply of 30 sachets in a plastic bottle with a MEMS cap and instructed them to add the contents of a single-serve sachet to the child's semi-solid, readyprepared foods every day for a period of 30 days. The main staple food consumed by pre-school children was uji made from locally milled flour from either maize or sorghum grains. The grains are not de-germed and sifted and so have high contents of phytic acid and phenolic compounds [37, 38]. At the research clinic, the assistants showed parents how to mix the contents of the first sachet with uji. This first dose was consumed at the research facility, and trained research assistants closely observed that each child consumed all the uji. Parents were given a mosquito net and instructed to immediately inform research assistants whenever a child fell sick. Research assistants conducted weekly pre-announced home visits to check if parents were adhering to instructions given at randomisation. Sick children found in the homes were referred to the research clinic. Children with fever $\left(\geq 37^{\circ} \mathrm{C}\right)$ and who tested positive for Plasmodium infection by microscopic examination of blood smears were treated immediately with artemisinin-lumefantrine; during treatment, these children were temporarily discontinued from the intervention treatment until medication was completed and subsequent microscopic examination of blood smears conducted after 7 days showed negative for malaria parasites.

Parents who withdrew children from the intervention were asked for reasons and permission to keep and analyse data and samples already collected. After 30 days of intervention, the phlebotomist collected venous blood $(4 \mathrm{~mL})$ and processed samples as stated above (Data collection time lines and field procedures). Medical staff examined every child, and fieldworkers collected anthropometric data, plastic bottles with the MEMS cap and empty sachets and administered a questionnaire to parents to collect additional information on possible factors affecting adherence. Once all data and samples were collected, the trial coordinator opened the sealed brown envelope to find out the child's intervention group (either iron or placebo).

\section{Post-intervention period}

For ethical reasons, children in the placebo group were given a 3-day course of dihydroartemisinin-piperaquine and a subsequent 30-day course of home fortification with $12.5 \mathrm{mg}$ iron as encapsulated ferrous fumarate. Children in the iron group were retained without fortification powders to monitor the population decline in haemoglobin concentration over time in a 100-day follow-up period. Parents were requested to take each child home and bring them back to the research clinic on a date generated by a pre-programmed Microsoft Excel software that randomly selected a date of their return visit within a 100-day period. On the return visit, a capillary blood sample was collected by finger puncture to measure haemoglobin concentrations in duplicate from a single drop and to store DNA on collection cards for subsequent assessment by PCR assay of Plasmodium parasites. Immediately, these children were withdrawn from further study and received appropriate medication if sick, a therapeutic course of dihydroartemisinin-piperaquine and a supply of sachets for daily home fortification with $12.5 \mathrm{mg}$ iron as encapsulated ferrous fumarate for another 30 days.

\section{Laboratory analysis}

We determined haemoglobin concentration (HemoCue 301, Ängelholm, Sweden) and zinc protoporphyrin (ZPP)-haem molar ratio (AVIV, model 206D, Lakewood NJ, USA) in whole blood and in erythrocytes as a marker of iron-deficient erythropoiesis, each in triplicate. We assayed Plasmodium antigenaemia by histidine-rich protein 2 (HRP2) and lactate dehydrogenase (LDH) tests and transferred aliquots of whole blood $(125 \mu \mathrm{L})$ on DNA collection cards (FTA Mini Card, catalogue WB120055, GE Healthcare, Little Chalfont, UK) for storage at ambient temperature and subsequent detection by PCR of Plasmodium infection; we also prepared thick and thin blood smears to allow for detection and counting of Plasmodium parasites. Iron markers (plasma concentrations of ferritin, soluble transferrin receptor and transferrin), inflammation markers (plasma concentrations of C-reactive protein (CRP) and $\alpha_{1}$-acid glycoprotein), albumin and vitamin B12 were measured at Meander Medical Centre, Amersfoort, The Netherlands, on an Abbott Architect C16000 and i2000 SR analyser as per manufacturer's instructions. 


\section{Statistical analysis}

Details of the statistical analysis are presented in a supplementary paper (Additional file 1). Data were double entered, checked for completeness and verified for possible entry errors using Microsoft Excel. Anthropometric indices and electronic adherence data were analysed using WHO Anthro software v.3.2.2 (World Health Organisation, Geneva, Switzerland) and PowerView v.3.5.2 (AARDEX Group Ltd, Sion, Switzerland), respectively. The final statistical analysis was conducted using SPSS 21 (IBM, Armonk, NY, USA) and CIA 2.2.0 (https://eprints.soton.ac.uk/393017/). To assess EDTA intake at home fortification levels of $3 \mathrm{mg}$ iron as $\mathrm{NaFeEDTA}$, we calculated the intake of iron per kilogram of body weight for all children in the trial, both at baseline and at 30 days after intervention. The corresponding intake of NaFeEDTA $\left(\mathrm{NaFeC}_{10} \mathrm{H}_{12} \mathrm{~N}_{2} \mathrm{O}_{8}\right)$ was calculated as intake iron $\times\left(\right.$ molecular weight $_{\mathrm{EDTA}} /$ molecular weight $\left._{\text {Iron }}\right)$ $=$ intake iron $\times(288.21 / 55.88)$. From these results, we assessed the prevalence of EDTA intake exceeding the upper level of the acceptable daily intake (ADI) (i.e. the amount of a food additive, expressed on a body weight basis, that can be ingested daily over a lifetime without appreciable health risk [39]) to be $1.9 \mathrm{mg} / \mathrm{kg}$ body weight [40].

The definitions we used were anaemia: haemoglobin concentration <110 g/L [41]; iron deficiency: plasma ferritin concentration $<12 \mu \mathrm{g} / \mathrm{L}$ [42]; Plasmodium infection: presence of parasites and gametocytes of any Plasmodium species [43]; inflammation: plasma CRP concentration $>5 \mathrm{mg} / \mathrm{L}$ [44] or plasma $\alpha_{1}$-acid glycoprotein concentration $>1.0 \mathrm{~g} / \mathrm{L}$ [45], respectively. Group adherence was defined as the proportion of children who consumed $\geq 24$ home fortification doses, corresponding to $\geq 80 \%$ of the 30 scheduled doses [46], with exclusion of children who were lost to follow-up because they moved out of the study area.

Variation of outcomes with a log-normal distribution was expressed as geometric standard deviation (GSD), i.e. a multiplicative factor such that division or multiplication of the geometric mean by this ratio indicates a variation that is equivalent to subtraction or addition of one standard deviation on a log-transformed scale [47].

Plasma ferritin concentration can be elevated by inflammation independently of iron status. Thus, when estimating the prevalence of iron deficiency, we accounted for inflammation by two methods. First, we restricted the analysis to children without inflammation. This method has the disadvantages that it leads to a reduced statistical precision (because of the reduced sample size) and it may produce biased results (if the true prevalence of iron deficiency differs between those with and without inflammation). Second, we used linear regression to adjust plasma ferritin concentrations for plasma concentrations of CRP and $\alpha_{1}$-acid glycoprotein concentration. We used the following formula for adjustment: $\log _{\mathrm{e}}\left(\right.$ ferritin $\left._{\text {adjusted }}\right)=\log _{\mathrm{e}}\left(\right.$ ferritin $\left._{\text {unadjusted }}\right)-$ $\beta_{1}\left[\log _{\mathrm{e}}\left(C R P_{\text {observed }}\right)-\log _{\mathrm{e}}\left(\mathrm{CRP} \mathrm{P}_{\text {reference }}\right)\right]-\beta_{2}\left[\log _{\mathrm{e}}(\mathrm{AG}-\right.$ $\left.\left.\mathrm{P}_{\text {observed }}\right)-\log _{\mathrm{e}}\left(\mathrm{AGP} \mathrm{P}_{\text {reference }}\right)\right]$; the results were then exponentiated to express ferritin concentrations in their natural units. The formula given here is similar to what was recently proposed [48]; however, we used logtransformed values because of the linear relationship that has been observed between log-ferritin and logCRP, as well as between $\log$-ferritin and $\log -\alpha_{1}$-acid glycoprotein (Suchdev, personal communication, 2016; and also the present study (not shown)). We used $15 \mathrm{mg} / \mathrm{L}$ and $2.59 \mathrm{~g} / \mathrm{L}$ as reference values for CRP and $\alpha_{1}$-acid glycoprotein, respectively, because these values were reported as the upper limits of the $95 \%$ reference range in healthy French children aged 3-5 years [49]. We implicitly assumed that higher upper values for reference ranges, as can be observed in their peers in developing countries, are due to infections and other inflammation-inducing disorders.

The objective of non-inferiority was determined by comparing end points obtained by both intention-totreat and per protocol analyses. We visually inspected histograms to assess whether outcome variables were normally distributed within intervention groups. Outcome variables with a log-normal distribution were log-transformed; exponentiation of group differences in log-transformed outcomes resulted in associations being expressed as relative differences. Outcomes that were not normally distributed, even after log-transformation, were compared using non-parametric tests. We estimated effects; $p$ values, where reported, are two-sided.

For the primary analysis, we estimated the difference in haemoglobin concentrations at the end of the 30-day fortification period between groups of children allocated to different iron formulations. Analysis was done using analysis of variance (ANOVA) and multiple linear regression analysis. As pre-planned, we accepted noninferiority only when all of the following conditions were met: (1) home fortification with $3 \mathrm{mg}$ iron as NaFeEDTA was superior to placebo (proof of efficacy); (2) home fortification with $12.5 \mathrm{mg}$ iron as encapsulated ferrous fumarate was superior to placebo (proof of assay sensitivity); and (3) the lower limit of the 95\% confidence interval (CI) around the difference in haemoglobin concentration between the groups who received home fortification with the two different iron formulations excluded the non-inferiority margin of $4.7 \mathrm{~g} / \mathrm{L}$, in both intention-to-treat and per protocol analyses (proof of efficacy).

For the secondary analysis, we used stratified analysis and multiple linear regression models to control for group imbalances of baseline factors that were strongly 
or moderately associated with primary outcome and were likely to influence the effect estimates. These baseline factors were plasma ferritin concentration, plasma soluble transferrin receptor concentration and age.

\section{Subgroup analysis}

Because iron absorption is known to depend on iron status, we considered iron markers at baseline (anaemia, iron status) as potential modifiers for intervention effects on haemoglobin concentration and plasma ferritin concentration at the end of the 30-day intervention period. Stratified analysis was used to measure effect sizes within subgroups; evidence for group differences in intervention effects was formally investigated in multiple linear regression models that included intervention and each baseline factor as main terms, as well as their product term. We conducted all three possible paired group comparisons (12.5 $\mathrm{mg}$ iron as ferrous fumarate versus $3 \mathrm{mg}$ iron as NaFeEDTA; $12.5 \mathrm{mg}$ iron as ferrous fumarate versus placebo; $3 \mathrm{mg}$ iron as NaFeEDTA versus placebo). In these analyses, we adjusted for plasma concentrations of ferritin and transferrin receptor at baseline (both as continuous variables); in the analysis of plasma ferritin concentration at 30 days after start of intervention, these baseline variables were log-transformed because this gave a better model fit than the untransformed variables.

\section{Meta-analysis}

We conducted a meta-analysis of randomised controlled trials in pre-school children to assess the effect of home fortification with iron-containing powders on anaemia and haemoglobin concentration at end of intervention. The methods are described in Additional file 2.

\section{Results}

\section{Flow of participants}

Of 433 children who were invited for screening, 366 children met the criteria for pre-medication administration and 338 children were randomised. Of these, 315 (93.5\%) completed 30 days of the intervention period and were included in the per protocol analysis (Fig. 1). Reasons for loss to follow-up were refusal by parents $(n=8)$, moving out of the study area $(n=6)$ and unknown $(n=9)$.

A total of 80 children became sick during the 30-day intervention period. We found no evidence that the proportion of sick children varied between intervention groups $(p=0.13)$. The most common infections were uncomplicated malaria with upper respiratory tract infections (24), severe malaria (14), upper respiratory tract infections (11) and uncomplicated malaria (8). Overall, $200(60.6 \%)$ of the children consumed more than $80 \%$ $(>24)$ of 30 scheduled sachets, and there was no evidence that this percentage differed between intervention groups $(p=0.99)$.

\section{Baseline characteristics}

The intervention groups were similar with respect to baseline characteristics (Table 2). Overall, the mean age was 23.6 months; $62.1 \%$ of children had anaemia. Inflammation as indicated by elevated concentrations of CRP or $\alpha_{1}$-acid glycoprotein occurred in $66.9 \%$ (226/ 338 ) of children. The prevalence of iron deficiency was $17.1 \%(57 / 333)$ or $42.5 \%(57 / 134)$, depending on whether or not children with inflammation were excluded from analysis. With ferritin concentrations adjusted for inflammation by linear regression, the prevalence of iron deficiency was 53.2\% (177/333). Of 366 blood samples assessed for the presence of $P$. falciparum by microscope or rapid dipstick tests (HRP2 or P. falciparum-specific pLDH), $40.7 \%$ and $36.4 \%$ of children were positive, respectively, with a median $\left(25^{\text {th }}, 75^{\text {th }}\right.$ percentiles $)$ density of asexual parasites of $1410(207,682) \mu / \mathrm{L}$. The prevalence of being stunted, wasted and underweight was $30.1 \%, 3.3 \%$ and $13.9 \%$, respectively.

\section{EDTA intake}

Home fortification with $3 \mathrm{mg}$ iron as NaFeEDTA resulted in a mean intake (SD) of $1.48(0.24)$ EDTA/kg body weight and 1.44 (0.23) EDTA/kg body weight at baseline and at 30 days after the start of intervention, respectively (Fig. 2). Correspondingly, assuming that this intake follows a normal distribution, $4.0 \%$ and $2.0 \%$ of children would exceed the ADI for EDTA of $1.9 \mathrm{mg} / \mathrm{kg}$ body weight.

\section{Intervention effects}

In the per protocol analysis, there was no evidence that home fortification for 30 days, whether using a daily dose of $3 \mathrm{mg}$ iron as NaFeEDTA or $12.5 \mathrm{mg}$ iron as ferrous fumarate, was efficacious in improving haemoglobin concentration, plasma ferritin concentration, plasma transferrin receptor concentration or erythrocyte ZPP-haem ratio (Table 3). Adjustment for baseline factors that were prognostic for haemoglobin concentration did not substantially change intervention effects (haemoglobin concentration difference of $1.3 \mathrm{~g} / \mathrm{L}(-1.8 \mathrm{~g} / \mathrm{L}$ to $4.3 \mathrm{~g} / \mathrm{L}$ ). Similarly, the intention-to-treat analysis (Additional file 3: Table S2) led to virtually identical results as obtained by per protocol analysis, and restriction of the analysis to children without inflammation led to similar effect estimates on haemoglobin concentration $(0.9 \mathrm{~g} / \mathrm{L},-4.1$ to $5.9 \mathrm{~g} / \mathrm{L}$ and $2.3 \mathrm{~g} / \mathrm{L},-3.1$ to $7.8 \mathrm{~g} / \mathrm{L}$ for $3 \mathrm{mg}$ iron as NaFeEDTA and $12.5 \mathrm{mg}$ iron as ferrous fumarate, respectively). Given these results, we conducted no further analysis to demonstrate non-inferiority of $3 \mathrm{mg}$ iron as NaFeEDTA.

Compared to placebo, home fortification with $3 \mathrm{mg}$ iron as NaFeEDTA seemed to reduce the prevalence of iron deficiency by $20.2 \%$ (Table 4 ); one-quarter of children who 


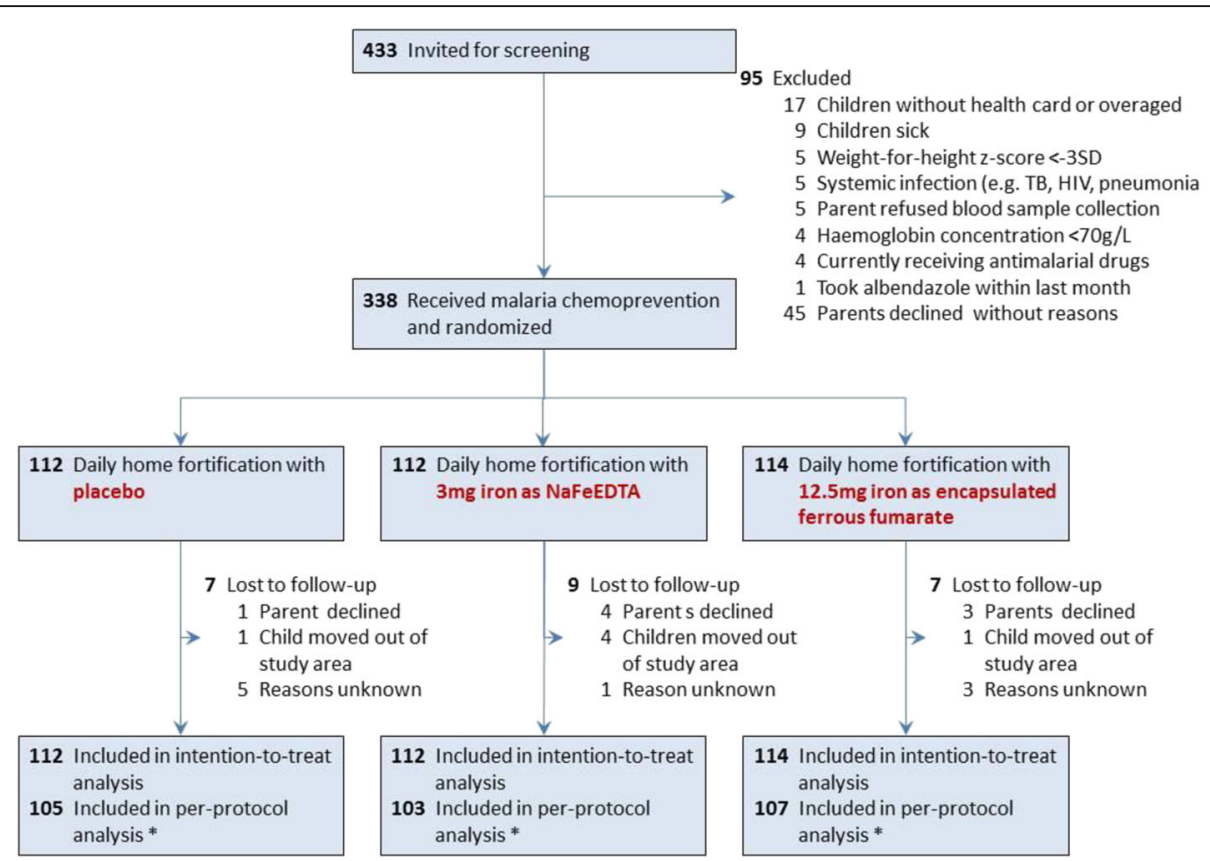

Fig. 1 Participant flow through the trial. *Sample sizes below number indicated are due to missing values, which varied by outcome. In the intention-to-treat analysis, missing values were replaced by multiple imputation

received this iron formulation nonetheless remained anaemic after 30 days. Home fortification with $12.5 \mathrm{mg}$ iron as ferrous fumarate seemed to reduce the prevalence of iron deficiency by $14.1 \%$ (95\% CI: -3.5 to $30.7 \%$ ), but the statistical evidence for such a reduction, as judged by the $95 \% \mathrm{CI}$, was weak. There was no evidence that either of the iron interventions affected the prevalence of anaemia, which affected one-half of children at the end of the 30-day intervention period, or the prevalence of Plasmodium infection, which remained at 16.4-19.1\%, depending on the method of assessment.

\section{Subgroup analysis}

There was no evidence that the effect of home fortification with iron, whether administered at a daily dose of $3 \mathrm{mg}$ iron as NaFeEDTA or $12.5 \mathrm{mg}$ iron as encapsulated ferrous fumarate, on haemoglobin concentration or plasma ferritin concentration was modified by iron status or anaemia status at baseline (see Figs. 3 and 4). The effect of home fortification with $12.5 \mathrm{mg}$ iron as ferrous fumarate on increased plasma ferritin concentration seemed larger in children without inflammation than in their peers with inflammation at baseline (89\% versus $3 \%)$, but the statistical evidence of such an effect modification was weak ( $p$ interaction: 0.17; Fig. 4).

\section{Meta-analysis}

The effect on haemoglobin concentration was highly heterogeneous $\left(I^{2}: 8.1 \% ; p\right.$ value for test of heterogeneity: <0.0001; Additional file 2: Figure S4). The pooled effect on haemoglobin concentration was $3.9 \mathrm{~g} / \mathrm{L}$ (95\% CI: $2.2-5.50 \mathrm{~g} / \mathrm{L})$, indicating that in a random sample of a hypothetically infinite number of trials, each estimating a different true underlying effect, one may on average expect an increase in haemoglobin concentration by $3.9 \mathrm{~g} / \mathrm{L}$, with the $95 \% \mathrm{CI}$ excluding an effect beyond $5.5 \mathrm{~g} / \mathrm{L}$.

\section{Discussion}

We found no evidence that daily home fortification for 30 days with a daily dose of either $3 \mathrm{mg}$ iron as NaFeEDTA or $12.5 \mathrm{mg}$ iron as encapsulated ferrous fumarate was efficacious in improving haemoglobin concentration or iron markers (plasma ferritin concentration, plasma soluble transferrin receptor concentration or erythrocyte ZPP-haem ratio). Compared to placebo, however, home fortification with $3 \mathrm{mg}$ iron as $\mathrm{NaFeEDTA}$ reduced the prevalence of iron deficiency by $20.2 \%$ (44.6\% versus 24.5\%; Table 4). Meta-analysis of trial results indicates a small, heterogeneous effect of home fortification with iron-containing powders on haemoglobin concentration.

Dichotomising a continuous outcome variable has the disadvantages that individuals close to but on opposite sides of the cut-off value are characterised as being very different rather than very similar [50], and that the prevalence difference depends on the cut-off value used for dichotomisation of the outcome [51]. Thus, in our study, a small group difference in the distribution of plasma ferritin concentration may misleadingly result in 
Table 2 Baseline characteristics, by intervention group

\begin{tabular}{|c|c|c|c|}
\hline Characteristic & Placebo & $\begin{array}{l}\text { Iron, } 3 \text { mg as } \\
\text { NaFeEDTA }\end{array}$ & $\begin{array}{l}\text { Iron, } 12.5 \mathrm{mg} \text { as } \\
\text { ferrous fumarate }\end{array}$ \\
\hline Number $(n)$ & 112 & 112 & 114 \\
\hline \multicolumn{4}{|l|}{ General characteristics } \\
\hline Sex, male & $69(61.6 \%)$ & $61(54.5 \%)$ & $56(49.1 \%)$ \\
\hline Age, months & $22.8(6.8)$ & $23.2(6.2)$ & $24.9(6.4)$ \\
\hline \multicolumn{4}{|l|}{ Age class } \\
\hline $12-23$ months & $61(54.5 \%)$ & $57(50.9 \%)$ & $44(38.6 \%)$ \\
\hline 24-36 months & $51(45.5 \%)$ & $55(49.1 \%)$ & $70(61.4 \%)$ \\
\hline \multicolumn{4}{|l|}{ Nutritional markers } \\
\hline Haemoglobin concentration, $\mathrm{g} / \mathrm{L}$ & $104.4(13.2)$ & $105.9(13.3)$ & $104.7(13.3)$ \\
\hline \multicolumn{4}{|l|}{ Anaemia } \\
\hline Moderate (haemoglobin concentration 70-99.99 g/L) & $33(29.5 \%)$ & $34(30.4 \%)$ & $36(31.6 \%)$ \\
\hline Mild (haemoglobin concentration 100-109.99 g/L) & $39(34.8 \%)$ & $31(27.7 \%)$ & $37(32.5 \%)$ \\
\hline No anaemia (haemoglobin concentration $\geq 110 \mathrm{~g} / \mathrm{L}$ ) & $40(35.7 \%)$ & $47(42.0 \%)$ & $41(36.0 \%)$ \\
\hline \multicolumn{4}{|l|}{ ZPP:haem ratio, $\mu \mathrm{mol}: \mathrm{mol}^{\mathrm{a}}$} \\
\hline In whole blood & $170(119 ; 305)$ & $172(102 ; 260)$ & $196(137 ; 283)$ \\
\hline In erythrocytes & $130(84 ; 301)$ & $141(76 ; 223)$ & $160(101 ; 246)$ \\
\hline Plasma ferritin concentration, $\mu \mathrm{g} / \mathrm{L}^{\mathrm{a}, \mathrm{b}}$ & $37.7(17.3 ; 74.0)$ & $31.4(16.0 ; 56.6)$ & $36.9(17.6 ; 68.8)$ \\
\hline \multicolumn{4}{|l|}{ Iron status ${ }^{b}$} \\
\hline Deficient (plasma ferritin concentration $<12 \mu \mathrm{g} / \mathrm{L}$ ) & $17(15.2 \%)$ & $20(18.3 \%)$ & $20(17.9 \%)$ \\
\hline $\begin{array}{l}\text { Replete (plasma ferritin concentration } \geq 12 \mu \mathrm{g} / \mathrm{L} \text { in } \\
\text { the absence of inflammation) }\end{array}$ & $26(23.2 \%)$ & $32(29.4 \%)$ & $19(17.0 \%)$ \\
\hline $\begin{array}{l}\text { Uncertain (plasma ferritin concentration } \geq 12 \mu \mathrm{g} / \mathrm{L} \text { in } \\
\text { the presence of inflammation) }\end{array}$ & $69(61.6 \%)$ & $57(52.3 \%)$ & $73(65.2 \%)$ \\
\hline Iron deficiency, based on adjusted ferritin concentrations $s^{b, c}$ & $52.7 \%(59 / 112)$ & $57.8 \%(63 / 109)$ & $49.1 \%(55 / 112)$ \\
\hline Plasma soluble transferrin receptor concentration, $\mathrm{mg} / \mathrm{L}^{\mathrm{a}}$ & $2.41(1.75 ; 3.46)$ & $2.39(1.82 ; 3.16)$ & $2.60(1.93 ; 3.41)$ \\
\hline Plasma albumin concentration, $\mathrm{g} / \mathrm{L}$ & $34.6(3.9)$ & $35.0(3.5)$ & $34.7(4.1)$ \\
\hline Vitamin $\mathrm{B}_{12}$ concentration, $\mathrm{pmol} / \mathrm{L}$ & $391(291 ; 557)$ & $409(311 ; 569)$ & $401(315 ; 554)$ \\
\hline \multicolumn{4}{|l|}{ Infection and inflammation markers } \\
\hline Plasma C-reactive protein concentration, $\mathrm{mg} / \mathrm{L}^{\mathrm{a}}$ & $2.5(0.7 ; 7.6)$ & $2.5(0.6 ; 7.8)$ & $4.5(1.3 ; 11.0)$ \\
\hline Plasma $a_{1}$-acid glycoprotein concentration, g/ L $^{\mathrm{a}}$ & $1.20(0.90 ; 1.57)$ & $1.08(0.81 ; 1.47)$ & $1.17(0.97 ; 1.63)$ \\
\hline \multicolumn{4}{|l|}{ Inflammation } \\
\hline Plasma C-reactive protein concentration $>5 \mathrm{mg} / \mathrm{L}$ & $40(35.7 \%)$ & $35(31.3 \%)$ & $53(46.5 \%)$ \\
\hline Plasma $a_{1}$-acid glycoprotein concentration $>1 \mathrm{~g} / \mathrm{L}$ & $71(63.4 \%)$ & $63(56.3 \%)$ & $81(71.1 \%)$ \\
\hline $\begin{array}{l}\text { Plasma C-reactive protein concentration }>5 \mathrm{mg} / \mathrm{L} \text { or plasma } \\
a_{1} \text {-acid glycoprotein concentration }>1 \mathrm{~g} / \mathrm{L}\end{array}$ & $77(68.8 \%)$ & $65(58 \%)$ & $84(73.7 \%)$ \\
\hline \multicolumn{4}{|l|}{ Plasmodium antigenaemia, by rapid dipstick tests ${ }^{\mathrm{d}}$} \\
\hline P. falciparum (either HRP2 or P. falciparum-specific pLDH) & $39(35.1 \%)$ & $40(36.0 \%)$ & $43(38.1 \%)$ \\
\hline $\begin{array}{l}\text { Plasmodium species other than } P \text {. falciparum (pLDH specific for } \\
\text { P. malariae, P. ovale or P. vivax) }\end{array}$ & $1(0.9 \%)$ & $2(1.8 \%)$ & 0 \\
\hline Any Plasmodium species & $39(35.1 \%)$ & $41(36.9 \%)$ & $43(38.1 \%)$ \\
\hline \multicolumn{4}{|l|}{ Blood smear tests, by microscopy } \\
\hline Asexual or sexual forms of $P$. falciparum & $47(41.9 \%)$ & $49(43.8 \%)$ & $55(48.2 \%)$ \\
\hline $\begin{array}{l}\text { Asexual forms of both } P \text {. falciparum and human Plasmodium } \\
\text { spp. other than P. falciparum (i.e. P. malariae, P. ovale or P. vivax) }\end{array}$ & $2(1.8)$ & $1(0.8)$ & $2(1.8)$ \\
\hline Asexual parasite density for $P$. falciparum, $\mu / L^{a}$ & $757(172 ; 3972)$ & $3340(297 ; 20,023)$ & $1048(207 ; 6820)$ \\
\hline
\end{tabular}


Table 2 Baseline characteristics, by intervention group (Continued)

\begin{tabular}{|c|c|c|c|}
\hline Low $(<1000 \mu / L)$ & $17(15.2 \%)$ & $9(8.0 \%)$ & $19(16.7 \%)$ \\
\hline Medium (1000-9999 $\mu / L)$ & $12(10.7 \%)$ & $8(7.1 \%)$ & $15(13.2 \%)$ \\
\hline High $(\geq 10,000 \mu / L)$ & $3(2.7 \%)$ & $7(6.3 \%)$ & $5(4.4 \%)$ \\
\hline Gametocyte density, $\mu / L^{\mathrm{a}}$ & $326(49 ; 732)$ & $82(37 ; 120)$ & $1126(57 ; 2679)$ \\
\hline \multicolumn{4}{|l|}{ Anthropometric markers } \\
\hline Body height, $\mathrm{cm}$ & $80.9(5.9)$ & $82.1(5.7)$ & $82.4(5.1)$ \\
\hline Body weight, $\mathrm{kg}$ & $10.6(1.8)$ & $10.8(2.0)$ & $10.9(1.7)$ \\
\hline Height-for-age z-score, SD & $-1.42(1.47)$ & $-1.15(1.43)$ & $-1.43(1.31)$ \\
\hline Weight-for-height z-score, SD & $-0.10(1.05)$ & $-0.16(1.07)$ & $-0.14(0.93)$ \\
\hline Weight-for-age z-score, SD & $-0.81(1.18)$ & $-0.71(1.22)$ & $-0.86(1.09)$ \\
\hline Stunted (height-for-age $z$-score $<-2$ SD) & $34(30.4 \%)$ & $31(27.7 \%)$ & $37(32.5 \%)$ \\
\hline Wasted (weight-for-height z-score $<-2$ SD) & $3(2.7 \%)$ & $5(4.5 \%)$ & $2(1.8 \%)$ \\
\hline Underweight (weight-for-age $z$-score $<-2$ SD) & $19(17.0 \%)$ & $12(10.7 \%)$ & 15 (13.2\%) \\
\hline
\end{tabular}

a relatively large difference in prevalence of iron deficiency. For this reason, group differences in the prevalence of iron deficiency should be interpreted with caution, and more weight should be given to group differences in plasma ferritin concentrations.

Adherence to intervention was suboptimal, with a substantial proportion of children ( 40\%) having consumed $<80 \%$ of the scheduled sachets. We found no evidence of bias in effect estimates due to differences in baseline factors that were prognostic for haemoglobin concentration. Our failure to show efficacy for either compound was found in both the per protocol and intention-totreat analyses, was consistent across subgroups that were defined by anaemia and iron status and precluded further assessment of the non-inferiority of $3 \mathrm{mg}$ iron as NaFeEDTA compared to $12.5 \mathrm{mg}$ iron as encapsulated ferrous fumarate.

Despite a course of chemoprevention with dihydroartemisinin-piperaquine, a substantial proportion of children carried Plasmodium parasites at the end of the 30-day intervention period. When assessed by rapid dipstick tests, this proportion may be overestimated because the $P$. falciparum HRP2 protein can persist in circulation for several weeks after parasite clearance $[52,53]$. We nonetheless found a similar prevalence estimate by microscopy, suggesting recrudescence of infections or the occurrence of new infections. In 2015, WHO revised the recommended target oral doses for malaria treatment with dihydroartemisinin and piperaquine in children, in recognition that the previously recommended dosage schedule (which was used in the present study) may be inadequate and may predispose children to an increased risk of treatment failure [54]. In addition, poor adherence to the second and third doses of dihydroartemisinin-piperaquine administered by parents at home may also have contributed to the recurrence of malaria. Future studies should consider direct observation of adherence to all doses during the entire course.

We selected a relatively short 30-day intervention with iron in the expectation that pre-medication with dihydroartemisinin-piperaquine would prevent malaria during this period, with a long-term view that the protection afforded by repeated chemoprevention with this combination drug would allow time windows for safe administration of short courses of iron intervention. The duration of protection of a single course of dihydroartemisinin-piperaquine is likely to vary between individuals and populations, depending, among other things, on variance in absorption and disposition of piperaquine and levels of acquired immunity (and thus on age and frequency and duration of exposure to Plasmodium infection). In a recent study among pre-school children in Burkina Faso, two cycles of chemoprevention with dihydroartemisinin-piperaquine, administered at the same target dose as in our study, resulted in a protection against malaria that persisted at a high level for 3 to 4 weeks and decreased rapidly thereafter, highlighting the importance of strict timing to ensure that children receive treatment at monthly intervals [55].

Our data show that the fortification dose of $3 \mathrm{mg}$ iron as NaFeEDTA cannot be increased without a substantial proportion of children in this age range exceeding the ADI for EDTA. It has been argued, however, that this ADI may have been set too low [56], and a recent trial 

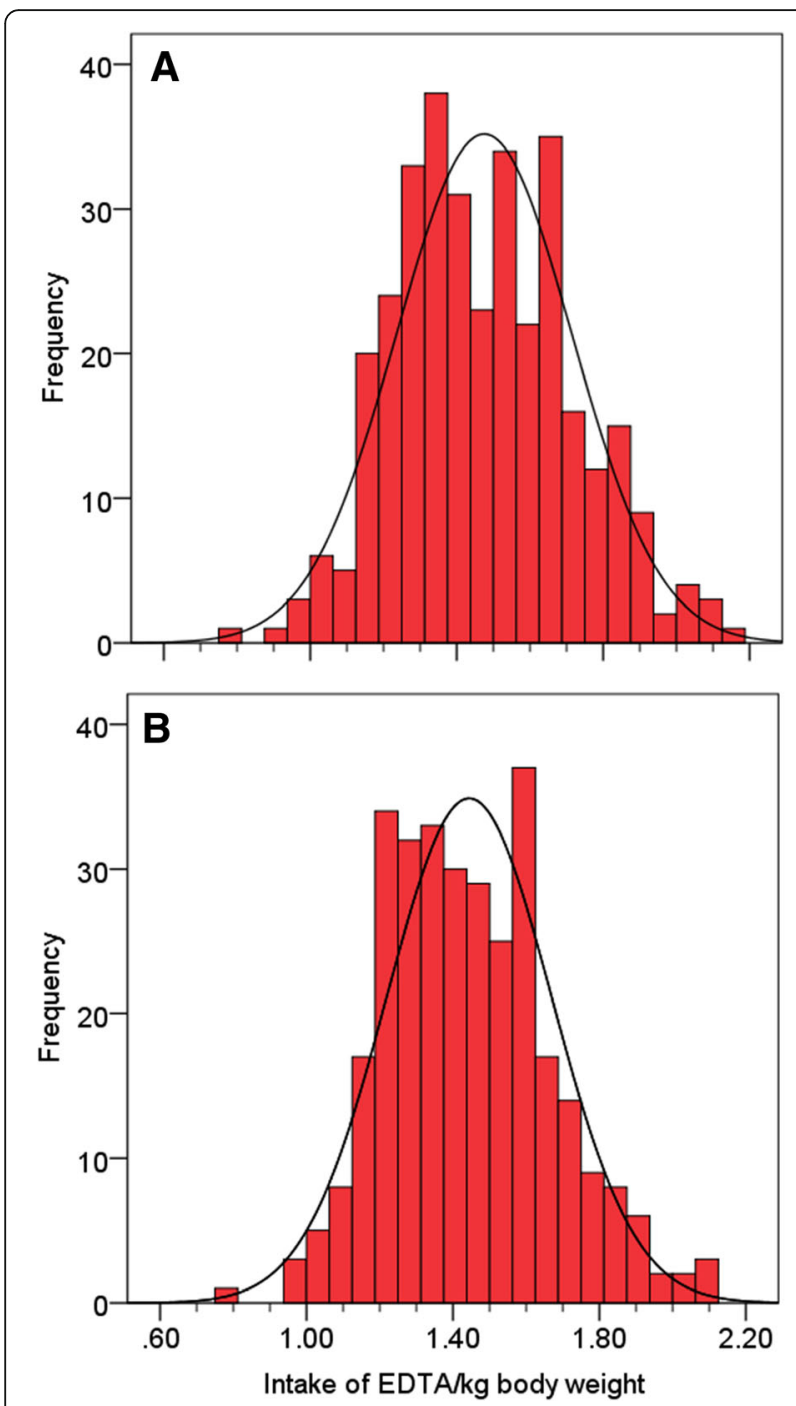

Fig. 2 EDTA intake at daily home fortification levels of $3 \mathrm{mg}$ iron as NaFeEDTA, at baseline (a) and at 30 days after start of intervention (b). The acceptable daily intake (ADI) for EDTA is $<1.9 \mathrm{mg} / \mathrm{kg}$ body weight

in Moroccan children has shown that daily oral intake of EDTA can reduce blood lead concentrations [57], which is important in view of the enormous public health burden due to lead exposure in developing countries.

The question may be raised whether our intervention period of 30 days was too short to show an effect on haemoglobin concentrations. In an earlier placebocontrolled randomised trial among Kenyan children aged 2-36 months, it was shown with a smaller sample size (79 iron; 76 placebo) than the present study that weekly supplementation with $6 \mathrm{mg}$ elemental iron as ferrous fumarate per kilogram body weight improved haemoglobin concentration at 4 weeks after the start of intervention [58]. Several other trials with longer intervention periods of home fortification also failed to demonstrate haematological response to home fortification with iron. For instance, a randomised trial in 6-month old Kenyan infants showed no effect of daily home fortification with $2.5 \mathrm{mg}$ iron as EDTA on haemoglobin concentration after 6 and 12 months of intervention [59]. Similarly, a trial conducted among Ghanaian children aged 8-20 months failed to show an effect on haemoglobin concentration after 6 months of daily home fortification with $40 \mathrm{mg}$ elemental iron as microencapsulated ferrous fumarate [60]. These findings suggest that there are other underlying factors that may cause a lack of effect of iron interventions on haemoglobin concentration.

Inflammation was highly prevalent and is known to reduce iron absorption. In our subgroup analysis, however, there was no evidence that inflammation at baseline influenced the magnitude of the effect of iron interventions on haemoglobin concentration, and only weak evidence $(p=0.17)$ that it decreased the effect of home fortification with $12.5 \mathrm{mg}$ iron as ferrous fumarate on plasma ferritin concentration. However, the cut-off definition for inflammation levels has not been validated in children, so there is a possibility that iron absorption was impaired at levels of inflammatory markers within the normal range (plasma CRP concentration $<5 \mathrm{mg} / \mathrm{L}$ or plasma $\alpha_{1}$-acid glycoprotein concentration $<1.0 \mathrm{~g} / \mathrm{L}$ ). Chronic infections caused by either viruses or low bacterial and parasitic loads can increase the inflammatory cytokine-mediated production of hepcidin, thus blocking iron absorption, in the absence of evident inflammation (Rita Wegmuller, personal communication, 25 May 2016). The notion that infection-induced inflammation can reduce iron absorption is supported by the findings of a study conducted among Gambian children aged 18-36 months, which showed elevated serum CRP concentrations and impaired absorption of orally supplemented iron in children with post-malarial anaemia compared with those with non-malarial anaemia, but serum CRP concentrations had reversed and iron absorption was recovered at 2 weeks after antimalarial treatment [61]. Another study among Kenyan infants showed that both low doses (2.5 mg iron as NaFeEDTA) and a high dose (12.5 mg iron as ferrous fumarate) increased the pathogenic profile of gut bacteria and gut inflammation [7].

Other factors that may have contributed to our failure to show efficacy are high contents of iron-inhibiting factors such as phytates and polyphenolic compounds in the food vehicles used for home fortification and suboptimal adherence to the daily home fortification with iron-containing powders.

The use of placebo in non-inferiority trials is controversial. Some argue that it is unethical to use placebos in the context of established interventions that have been shown to be efficacious $[62,63]$. The Declaration of Helsinki (2013) asserts that 'the benefits, risks, burdens 
Table 3 Effect of daily home fortification with $3 \mathrm{mg}$ iron as NaFeEDTA and $12.5 \mathrm{mg}$ iron as encapsulated ferrous fumarate on continuous outcomes at 30 days after start of intervention, per protocol analysis

\begin{tabular}{|c|c|c|c|c|}
\hline Outcome/intervention group & No. $(n)$ & Estimate $^{a}$ & Effect $(95 \% \mathrm{Cl})$ relative to placebo ${ }^{\mathrm{b}}$ & Effect $(95 \% \mathrm{Cl})$ relative to standard ${ }^{\mathrm{b}}$ \\
\hline \multicolumn{5}{|l|}{ Haemoglobin concentration } \\
\hline Placebo & 105 & $106.9 \mathrm{~g} / \mathrm{L}(13.3 \mathrm{~g} / \mathrm{L})$ & Reference & Not applicable \\
\hline Iron, $3 \mathrm{mg}$ as NaFeEDTA & 103 & $110.0 \mathrm{~g} / \mathrm{L}(12.5 \mathrm{~g} / \mathrm{L})$ & $3.0 \mathrm{~g} / \mathrm{L}(-0.2 \mathrm{~g} / \mathrm{L} \text { to } 6.2 \mathrm{~g} / \mathrm{L})^{\mathrm{c}}$ & $1.3 \mathrm{~g} / \mathrm{L}(-1.8 \mathrm{~g} / \mathrm{L} \text { to } 4.3 \mathrm{~g} / \mathrm{L})^{\mathrm{c}}$ \\
\hline Iron, $12.5 \mathrm{mg}$ as ferrous fumarate & 107 & $108.6 \mathrm{~g} / \mathrm{L}(12.0 \mathrm{~g} / \mathrm{L})$ & $1.6 \mathrm{~g} / \mathrm{L}(-1.6 \mathrm{~g} / \mathrm{L} \text { to } 4.8 \mathrm{~g} / \mathrm{L})^{c}$ & Reference \\
\hline \multicolumn{5}{|l|}{ Plasma ferritin concentration } \\
\hline Placebo & 104 & $29.7 \mu \mathrm{g} / \mathrm{L}[3.47]$ & Reference & Not applicable \\
\hline Iron, $3 \mathrm{mg}$ as NaFeEDTA & 102 & $33.7 \mu \mathrm{g} / \mathrm{L}[2.53]$ & $16.2 \%(-14.3 \% \text { to } 57.7 \%)^{d}$ & $2.5 \%(-22.4 \% \text { to } 35.4 \%)^{d}$ \\
\hline Iron, $12.5 \mathrm{mg}$ as ferrous fumarate & 105 & $32.6 \mu \mathrm{g} / \mathrm{L}[3.00]$ & $12.3 \%(-17.1 \% \text { to } 52.0 \%)^{d}$ & Reference \\
\hline \multicolumn{5}{|c|}{ Plasma soluble transferrin receptor concentration } \\
\hline Placebo & 105 & $2.24 \mathrm{mg} / \mathrm{L}[1.61]$ & Reference & Not applicable \\
\hline Iron, $3 \mathrm{mg}$ as NaFeEDTA & 103 & $2.15 \mathrm{mg} / \mathrm{L}[1.47]$ & $-4.3 \%(-13.5 \% \text { to } 5.9 \%)^{d}$ & $3.6 \%(-5.5 \% \text { to } 13.6 \%)^{d}$ \\
\hline Iron, $12.5 \mathrm{mg}$ as ferrous fumarate & 106 & 2.07 mg/L [1.38] & $-7.3 \%(-16.2 \% \text { to } 2.6 \%)^{d}$ & Reference \\
\hline \multicolumn{5}{|l|}{ Erythrocyte ZPP-haem ratio } \\
\hline Placebo & 104 & $136 \mu \mathrm{mol} / \mathrm{mol}[2.17]$ & Reference & Not applicable \\
\hline Iron, $3 \mathrm{mg}$ as NaFeEDTA & 103 & 127 umol/mol [1.97] & $-6.5 \%(-23.5 \% \text { to } 14.2 \%)^{d}$ & $-5.3 \%(-21.7 \% \text { to } 14.5 \%)^{d}$ \\
\hline Iron, $12.5 \mathrm{mg}$ as ferrous fumarate & 106 & $134 \mu \mathrm{mol} / \mathrm{mol}[2.00]$ & $-0.7 \%(-18.6 \% \text { to } 21.0 \%)^{d}$ & Reference \\
\hline
\end{tabular}

${ }^{\mathrm{a}}$ Mean (SD) or geometric mean [geometric standard deviation]

beffects were adjusted for study design (blocks nested within strata of haemoglobin concentration $<100 \mathrm{~g} / \mathrm{L}$ and $\geq 100 \mathrm{~g} / \mathrm{L}$ )

'Effects were calculated as absolute difference in means

${ }^{d}$ Exponentiation of group differences with log-transformed outcomes resulted in associations being expressed as relative differences

Table 4 Effect of daily home fortification with $3 \mathrm{mg}$ iron as NaFeEDTA and $12.5 \mathrm{mg}$ iron as encapsulated ferrous fumarate on categorical outcomes at 30 days after start of intervention, per protocol analysis

\begin{tabular}{|c|c|c|c|}
\hline Outcome/intervention group & Prevalence & $(n / n)$ & Effect $(95 \% \mathrm{Cl})$ relative to placebo \\
\hline \multicolumn{4}{|l|}{ Anaemia } \\
\hline Placebo & $53.3 \%$ & $(56 / 105)$ & Reference \\
\hline Iron, 3 mg as NaFeEDTA & $43.7 \%$ & $(45 / 103)$ & $-9.6 \%(-22.7 \%$ to $3.9 \%)$ \\
\hline Iron, $12.5 \mathrm{mg}$ as ferrous fumarate & $51.4 \%$ & $(55 / 107)$ & $-1.9 \%(-15.1 \%$ to $11.3 \%)$ \\
\hline \multicolumn{4}{|l|}{ Iron deficiency ${ }^{a}$} \\
\hline Placebo & $44.6 \%$ & $(25 / 56)$ & Reference \\
\hline Iron, 3 mg as NaFeEDTA & $24.5 \%$ & $(12 / 49)$ & $-20.2 \%(-36.4 \%$ to $-18.5 \%)$ \\
\hline Iron, $12.5 \mathrm{mg}$ as ferrous fumarate & $30.5 \%$ & $(18 / 59)$ & $-14.1 \%(-30.7 \%$ to $3.5 \%)$ \\
\hline \multicolumn{4}{|l|}{ Plasmodium infection, by dipstick test ${ }^{\mathrm{b}}$} \\
\hline Placebo & $16.2 \%$ & $(17 / 105)$ & Reference \\
\hline Iron, 3 mg as NaFeEDTA & $18.4 \%$ & $(19 / 103)$ & $2.3 \%(-8.1 \%$ to $12.6 \%)$ \\
\hline Iron, $12.5 \mathrm{mg}$ as ferrous fumarate & $22.6 \%$ & $(24 / 106)$ & $6.4 \%(-4.3 \%$ to $17.0 \%)$ \\
\hline \multicolumn{4}{|l|}{ P. falciparum infection, by microscopy } \\
\hline Placebo & $18.5 \%$ & $(19 / 103)$ & Reference \\
\hline Iron, $3 \mathrm{mg}$ as NaFeEDTA & $15.5 \%$ & $(15 / 97)$ & $-3.0 \%(-13.4 \%$ to $7.6 \%)$ \\
\hline Iron, $12.5 \mathrm{mg}$ as ferrous fumarate & $15.2 \%$ & $(15 / 99)$ & $-3.3 \%(-13.6 \%$ to $7.2 \%)$ \\
\hline
\end{tabular}

${ }^{a}$ Analysis restricted to children without inflammation (see text)

${ }^{b}$ Presence of HRP, pLDH specific to $P$. falciparum or pLDH due to human Plasmodium species other than $P$. falciparum 


\begin{tabular}{|c|c|c|c|c|c|c|c|c|c|c|}
\hline \multirow[b]{2}{*}{ Iron status } & \multicolumn{3}{|c|}{ Placebo } & \multicolumn{3}{|c|}{$\begin{array}{l}\text { 3mg iron } \\
\text { as NaFeEDTA }\end{array}$} & & Difference, $\mathrm{g} / \mathrm{L}(95 \% \mathrm{Cl})$ & \multirow[t]{2}{*}{ Difference, $\mathrm{g} / \mathrm{L}(95 \% \mathrm{Cl})$} & \multirow[t]{2}{*}{$\begin{array}{c}\mathbf{p}- \\
\text { interaction }\end{array}$} \\
\hline & $n$ & Mean & (SD) & $\mathrm{n}$ & Mean & \multicolumn{2}{|l|}{ (SD) } & & & \\
\hline Deficient & 17 & 101.1 & (16.5) & 16 & 103.0 & $(13.6)$ & & $\longmapsto$ & $-3.4(-13.3$ to 6.5$)$ & \multirow{3}{*}{0.15} \\
\hline Replete & 24 & 110.7 & (9.8) & 31 & 114.8 & (9.9) & & $\longmapsto$ & $5.5(-1.9$ to 12.8$)$ & \\
\hline Uncertain & 64 & 107.1 & (13.2) & 53 & 109.3 & (12.9) & & $\longmapsto$ & $3.5(-0.9$ to 7.9$)$ & \\
\hline \multicolumn{11}{|c|}{ Haemoglobin concentration } \\
\hline$<100 \mathrm{~g} / \mathrm{L}$ & 68 & 104.0 & (13.4) & 60 & 105.0 & (11.8) & & $\mapsto$ & $0.2(-3.7$ to 4.1$)$ & \multirow{2}{*}{0.29} \\
\hline$\geq 100 \mathrm{~g} / \mathrm{L}$ & 37 & 112.4 & (11.4) & 43 & 116.9 & $(10.0)$ & & $\longmapsto$ & $2.6(-2.6$ to 7.8$)$ & \\
\hline \multicolumn{11}{|c|}{ Inflammation } \\
\hline Absent & 33 & 109.8 & (10.1) & 43 & 112.8 & (10.7) & & $\mapsto \leftrightarrow$ & $2.0(-1.4$ to 5.5$)$ & \multirow{2}{*}{0.92} \\
\hline Present & 77 & 105.6 & (14.4) & 60 & 108.0 & (13.4) & & $\longmapsto$ & $3.7(-1.1$ to 8.5$)$ & \\
\hline \multirow[t]{3}{*}{ All children } & \multirow[t]{2}{*}{105} & \multirow[t]{2}{*}{106.9} & \multirow[t]{2}{*}{ (13.3) } & \multirow[t]{2}{*}{103} & \multirow[t]{2}{*}{110.0} & \multirow[t]{2}{*}{ (12.5) } & \multicolumn{2}{|r|}{$\mapsto$} & $2.4(-0.6$ to 5.4$)$ & \\
\hline & & & & & & & -20 & $0 \quad 10$ & 30 & \\
\hline & & Place & & & $\begin{array}{l}12.5 \mathrm{mg} \\
\text { errous } \mathrm{f}\end{array}$ & $\begin{array}{l}\text { iron } \\
\text { umarate }\end{array}$ & & Difference, $\mathrm{g} / \mathrm{L}(95 \% \mathrm{Cl})$ & Difference, $\mathrm{g} / \mathrm{L}(95 \% \mathrm{Cl})$ & $\begin{array}{c}\mathbf{p}- \\
\text { interaction }\end{array}$ \\
\hline Iron status & $\mathrm{n}$ & Mean & (SD) & $\mathrm{n}$ & Mean & (SD) & & & & \\
\hline Deficient & 17 & 101.1 & (16.5) & 18 & 108.6 & (12.5) & & $\longmapsto$ & $3.1(-5.3$ to 11.5$)$ & 0.68 \\
\hline Replete & 24 & 110.7 & $(9.8)$ & 17 & 112.0 & (9.8) & & $\longmapsto$ & $3.5(-4.6$ to 11.6$)$ & 0.00 \\
\hline Uncertain & 64 & 107.1 & (13.2) & 71 & 107.8 & (12.4) & & $\longmapsto$ & $1.1(-2.9$ to 5.1$)$ & \\
\hline Haemoglobin & & & & & & & & & & \\
\hline$<100 \mathrm{~g} / \mathrm{L}$ & 68 & 104.0 & (13.4) & 69 & 104.6 & (10.2) & & $\mapsto-$ & $-0.3(-4.0$ to 3.5$)$ & \\
\hline$\geq 100 \mathrm{~g} / \mathrm{L}$ & 37 & 112.4 & (11.4) & 38 & 115.8 & (11.8) & & $\longmapsto$ & $1.5(-4.1$ to 7.0$)$ & 0.42 \\
\hline Inflammation & & & & & & & & & & \\
\hline Absent & 33 & 109.8 & (10.1) & 28 & 112.8 & (10.2) & & $\mapsto \leftrightarrow$ & $-0.1(-3.2$ to 3.0$)$ & 88 \\
\hline Present & 77 & 105.6 & (14.4) & 79 & 107.1 & $(12.3)$ & & $\longmapsto$ & $1.5(-3.4$ to 6.3$)$ & 0.80 \\
\hline All children & 105 & 106.9 & (13.3) & 107 & 108.6 & (12.0) & & $\mapsto$ & $1.6(-1.4$ to 4.5$)$ & \\
\hline & & & & & & & -20 & 20 & 30 & \\
\hline
\end{tabular}

Fig. 3 Effect of interventions on haemoglobin concentration ( $\mathrm{g} / \mathrm{L}$ ) at 30 days after start of intervention, by subgroups of iron status and haemoglobin concentration class at baseline. Inflammation was defined to be absent when plasma C-reactive protein (CRP) concentration was $\leq 5 \mathrm{mg} / \mathrm{L}$ and plasma $a_{1}$-acid glycoprotein concentration was $\leq 1.0 \mathrm{~g} / \mathrm{L}$, and present when either plasma CRP concentration was $>5 \mathrm{mg} / \mathrm{L}$ or plasma $a_{1}$-acid glycoprotein concentration was $>1.0 \mathrm{~g} / \mathrm{L}$. Group means were obtained by one-way ANOVA. Intervention effects were adjusted for stratified block design as well as plasma concentrations of ferritin and soluble transferrin receptor at baseline (both continuous variables). The $p$ values indicate the two-sided probability that group effects are as different as observed or more extreme when assuming that they are identical

and effectiveness of a new intervention must be tested against those of the best proven intervention(s)' [64]. In our case, there was an established WHO recommendation for daily home fortification with $12.5 \mathrm{mg}$ iron as ferrous salt, based on a meta-analysis of six randomised controlled trials [3] that showed an overall reduction of the prevalence of anaemia.

We included a third arm with placebo, however, because we were concerned that established efficacious interventions do not consistently demonstrate superiority in placebo-controlled studies. Notably, one-third of meta-analyses that demonstrate a protective effect from interventions are not supported by subsequent large randomised controlled trials $[65,66]$. In addition, in the meta-analysis that formed the basis for the WHO recommendation for daily home fortification, three of six trials included could not exclude the absence of an effect on haemoglobin concentration. A trial among Ghanaian children, published after the meta-analysis but before we started our study, with a larger sample size than all previous studies combined, also failed to showed an effect of daily home fortification with $12.5 \mathrm{mg}$ iron as ferrous fumarate on either change in haemoglobin concentration or the prevalence of anaemia, despite $45 \%$ of children being iron deficient at baseline and good adherence to intervention [61]. Our use of a three-armed non-inferiority trial that includes a placebo arm is consistent with international recommendations [67] and is validated by our results: in the absence of a placebo group, we would erroneously have concluded that $3 \mathrm{mg}$ iron as NaFeEDTA was non-inferior to $12.5 \mathrm{mg}$ iron as encapsulated ferrous fumarate.

In our meta-analysis, we found a high level of heterogeneity in effects across trials. How should we interpret this finding? In the absence of evidence for an effect in single trials, meta-analysis is often understood to be the continuation of the pursuit of statistical significance by other means. A high level of heterogeneity indicates, however, that there is no single true effect in a single, common population that underlies the trials included in the meta-analysis. Heterogeneity may reflect methodological differences between trials (dosage, formulation and duration of intervention, adherence, study quality, etc.), but it may also indicate that there are different types of populations, each with different true underlying effects. Thus, the pooled random effect may not reflect the actual effect in any particular population being studied, and has little value other than perhaps providing some 


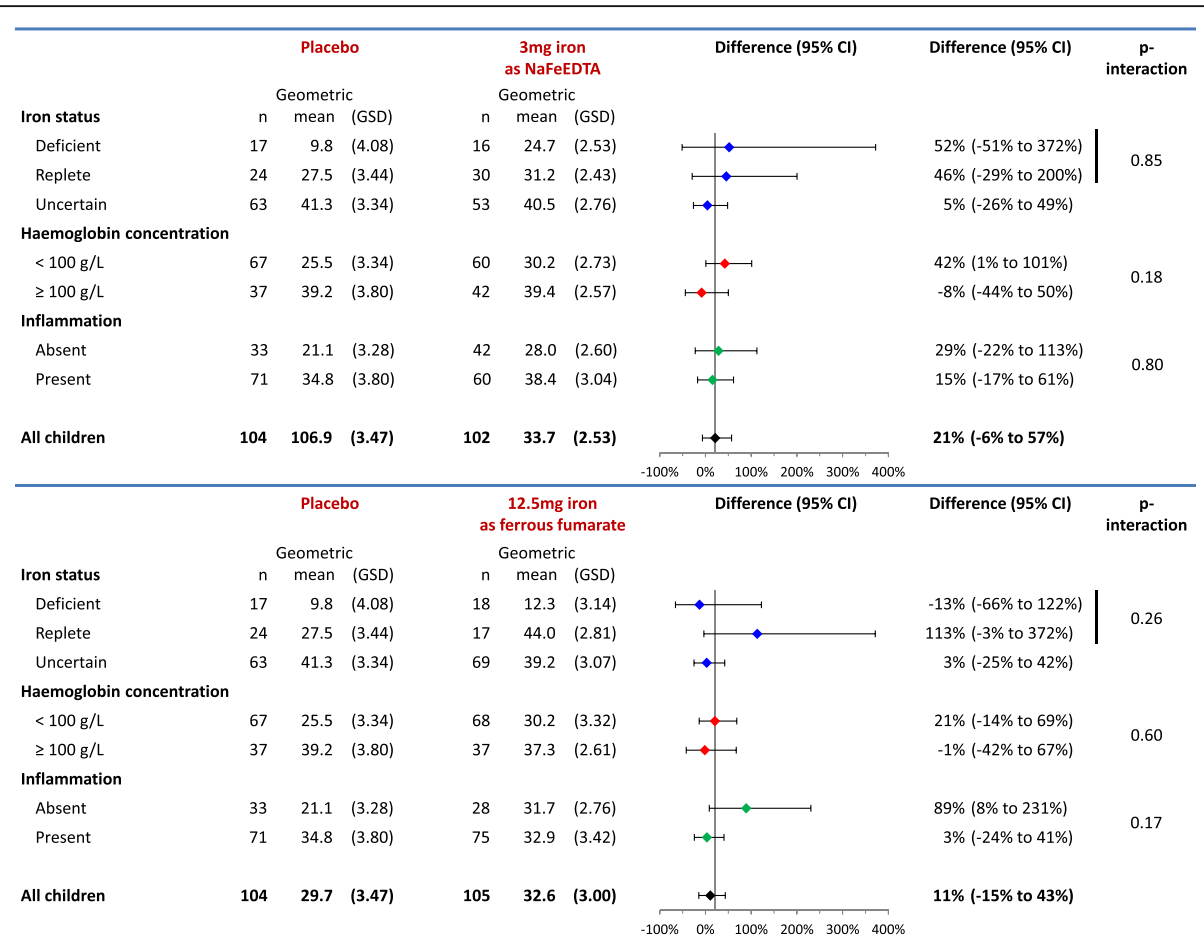

Fig. 4 Effect of interventions on plasma ferritin concentration $(\mu \mathrm{g} / \mathrm{L})$ at 30 days after start of intervention, by subgroups of iron status and haemoglobin concentration class at baseline. Inflammation was defined to be absent when plasma CRP concentration was $\leq 5 \mathrm{mg} / \mathrm{L}$ and plasma $a_{1}$-acid glycoprotein concentration was $\leq 1.0 \mathrm{~g} / \mathrm{L}$, and present when either plasma CRP concentration was $>5 \mathrm{mg} / \mathrm{L}$ or plasma $a_{1}$-acid glycoprotein concentration was $>1.0 \mathrm{~g} / \mathrm{L}$. Group geometric means were obtained by exponentiation of results of one-way ANOVA. Intervention effects were adjusted for stratified block design as well as plasma concentrations of ferritin and soluble transferrin receptor at baseline (both log-transformed continuous variables). Exponentiation of group differences with log-transformed outcomes resulted in associations being expressed as relative differences. GSD geometric standard deviation. The $p$ values indicate the two-sided probability that group effects are as different as observed or more extreme when assuming that they are identical

evidence to inform policy decisions. Our meta-analysis (Additional file 2: Figure S4) suggests a small gain in haemoglobin concentration in most trials, indicating that home fortification with iron-containing micronutrient powders provides some benefit across different settings. This gain may be insufficient to recommend home fortification in all settings, as illustrated by the main results of our trial. Our finding of heterogeneity between trial results should stimulate subgroup analysis or meta-regression to identify population-specific factors that determine efficacy (e.g. differences in prevalence of iron deficiency and inflammation, food content of compounds that inhibit iron absorption). Such approaches may become possible as evidence is accrued from a variety of studies in different settings.

\section{Conclusions}

In this population, home fortification with either $3 \mathrm{mg}$ iron as NaFeEDTA or $12.5 \mathrm{mg}$ iron as encapsulated ferrous fumarate was insufficiently efficacious to assess non-inferiority of $3 \mathrm{mg}$ iron as NaFeEDTA compared to $12.5 \mathrm{mg}$ iron as encapsulated ferrous fumarate. Our finding of heterogeneity between trial results should stimulate subgroup analysis or meta-regression to identify population-specific factors that determine efficacy.

\section{Additional files}

Additional file 1: Statistical analysis plan. (DOCX 109 kb)

Additional file 2: Effect of home fortification with iron-containing powders on anaemia and haemoglobin concentration in pre-school children: meta-analysis of randomised controlled trials. (DOCX $61 \mathrm{~kb}$ )

Additional file 3: Effect of daily home fortification with iron on haemoglobin concentration by intention-to-treat analysis. (DOCX 16 kb)

\section{Abbreviations}

ADI: Acceptable daily intake; AGP: $a_{1}$-acid glycoprotein; CRP: C-reactive protein; EDTA: ethylenediaminetetraacetate; EMA: European Medicine Agency; HF-TAG: Home Fortification Technical Advisory Group; HRP2: histidine-rich protein 2; MEMS: Medication Events Monitoring System; pLDH: Plasmodium lactate dehydrogenase

\section{Acknowledgements}

We thank the parents, children, staff and volunteers. In addition, we thank René Hampsink, Abbott Diagnostics, Hoofddorp, The Netherlands and Annet de Bats, Meander Medical Centre, Laboratory for Clinical Chemistry, Amersfoort, The Netherlands, for support in the biochemical analyses and Stephen Senn for statistical advice. 


\section{Funding}

We gratefully acknowledge support by Sight and Life (http://www. sightandlife.org/), a non-profit organisation established by Royal DSM, through a research grant and a personal grant to ET. In addition, DSM Nutrition Products (Johannesburg, South Africa) manufactured the supplements with micronutrient powders. Micronutrients other than iron were included in the supplements at the request of Sight and Life; the funder had no further role in study design, data collection and analysis, preparation of the manuscript or decision to publish. We thank the MRC-ING for supporting the study through an additional personal grant to ET.

\section{Availability of data and materials}

The datasets used and/or analysed during the current study are available from the corresponding author on reasonable request.

\section{Authors' contributions}

ET was involved in the study design and coordinated the implementation of the research project. PEA was involved in the study design and implementation. ST compiled the study protocol; VO conducted the laboratory analysis in Kenya, WO assisted in clinical aspects of the field work, and AYD conducted the biochemical analysis in The Netherlands. AMP reviewed the manuscript and provided technical inputs. HV conceived the idea and study design. Both ET and HV conducted the statistical analysis. All authors read and approved the final manuscript.

\section{Competing interests}

The authors declare that they have no competing interests.

\section{Consent for publication}

Not applicable.

\section{Ethics approval and consent to participate}

Ethical clearance was obtained from the London School of Hygiene and Tropical Medicine Ethical Committee, UK (reference 6503) and the Kenyatta National Hospital Ethical Review Committee, Kenya (reference KNH-ERC/A/402). The parents or primary guardians signed the consent form.

\section{Publisher's Note}

Springer Nature remains neutral with regard to jurisdictional claims in published maps and institutional affiliations.

\section{Author details}

${ }^{1}$ MRCG Keneba at MRC Unit, Banjul, The Gambia. ${ }^{2}$ MRC International Nutrition Group, Faculty of Epidemiology and Population Heath, London School of Hygiene and Tropical Medicine, Keppel Street, London WC1E 7HT, England, UK. ${ }^{3}$ Maseno University, School of Public Health and Community Development, Maseno, Kenya. ${ }^{4}$ International Centre of Insect Physiology and Ecology, Nairobi, Kenya. ${ }^{5}$ Division of Human Nutrition and Cell Biology and Immunology Group, Wageningen University, Wageningen, The Netherlands. ${ }^{6}$ Maseno University, School of Medicine, Maseno, Kenya. ${ }^{7}$ Meander Medical Centre, Laboratory for Clinical Chemistry and Haematology, Amersfoort, The Netherlands.

Received: 13 October 2016 Accepted: 20 March 2017

\section{Published online: 28 April 2017}

\section{References}

1. Use of multiple micronutrient powders for home fortification of foods consumed by infants and children 6-23 months of age. Geneva: World Health Organization; 2011. http://apps.who.int/iris/bitstream/10665/44651/1/ 9789241502047_eng.pdf. Accessed 8 Apr 2017.

2. Worldwide prevalence of anaemia 1993-2005: WHO Global Database on Anaemia. De Benoist, B, McLean E, Egli I, Cogswell M, editors. Geneva: World Health Organization; 2008. http://apps.who.int/iris/bitstream/10665/43894/1/ 9789241596657_eng.pdf. Accessed 30 Jan 2017.

3. De-Regil LM, Suchdev PS, Vist GE, Walleser S, Peña-Rosas JP. Home fortification of foods with multiple micronutrient powders for health and nutrition in children under two years of age. Cochrane Database Syst Rev. 2011;9:CD008959.

4. Nestel P, Alnwick D, for the International Nutritional Anaemia Consultative Group (INACG). Iron/multi-micronutrient supplements for young children: summary and conclusions of a consultation held at UNICEF, Copenhagen, August 19-20, 1996. Washington DC: ILSI Human Nutrition Institute; 1997. http://ilsirf.org/wp-content/uploads/sites/5/2016/04/INACG_Iron_MultiMicronutrient_Supplement-for-Young-Children.pdf. Accessed 9 Mar 2017.

5. Salam RA, MacPhail C, Das JK, Bhutta ZA. Effectiveness of micronutrient powders (MNP) in women and children. BMC Public Health. 2013;13(Suppl3):S22.

6. Soofi S, Cousens S, lqbal SP, Akhund T, Khan J, Ahmed I, Zaidi AKM, Bhutta ZA. Effect of provision of daily zinc and iron with several micronutrients on growth and morbidity among young children in Pakistan: a clusterrandomised trial. Lancet. 2013;382:29-40.

7. Jaeggi T, Kortman GA, Moretti D, Chassard C, Holding P, Dostal A, Boekhorst J, Timmerman HM, Swinkels DW, Tjalsma H, Njenga J, Mwangi A, Kvalsvig J, Lacroix C, Zimmermann MB. Iron fortification adversely affects the gut microbiome, increases pathogen abundance and induces intestinal inflammation in Kenyan infants. Gut. 2015;64:731-42.

8. Zlotkin S, Newton S, Aimone AM, Azindow I, Amenga-Etego S, Tchum K, Mahama E, Thorpe KE, Owusu-Agyei S. Effect of iron fortification on malaria incidence in infants and young children in Ghana: a randomized trial. JAMA. 2013;310:938-47.

9. Gera T, Sachdev HP. Effect of iron supplementation on incidence of infectious illness in children: systematic review. BMJ. 2002:325:1142.

10. Kortman GAM, Boleij A, Swinkels DW, Tjalsma H. Iron availability increases the pathogenic potential of Salmonella typhimurium and other enteric pathogens at the intestinal epithelial interface. PLoS One. 2012;7:e29968.

11. Zimmermann MB, Chassard C, Rohner F, N'goran EK, Nindjin C, Dostal A, Utzinger J, Ghattas H, Lacroix C, Hurrell RF. The effects of iron fortification on the gut microbiota in African children: a randomized controlled trial in Cote d'Ivoire. Am J Clin Nutr. 2010;92:1406-15.

12. Gill SK, Nguyen P, Koren G. Adherence and tolerability of iron-containing prenatal multivitamins in pregnant women with pre-existing gastrointestinal conditions. J Obstet Gynaecol. 2009;29:594-8.

13. Sölvell L. Oral iron therapy. Side effects. In: Hallberg L, Harwerth H-G, Vannotti A, editors. Iron deficiency: pathogenesis, clinical aspects, therapy. London: Academic Press; 1970. p. 573-83.

14. De Melo Machado KM, Cardoso Ferreira LO, Impieri de Souza A, Da Silva Diniz A. The side-effects of different doses of iron sulfate on women of reproductive age: a randomized double-blind, placebo-controlled study. Rev Bras Saude Mater Infant. 2011;11:275-81.

15. Kumar N, Chandhiok N, Dhillon BS, Kumar P. Role of oxidative stress while controlling iron deficiency anaemia during pregnancy — Indian scenario. Indian J Clin Biochem. 2009;24:5-14.

16. Verhoef $H$, Veenemans $J$. Safety of iron-fortified foods in malaria-endemic areas. Am J Clin Nutr. 2009;89:1949-50.

17. Ministry of Public Health and Sanitation. Kenya National Malaria Strategy Plan 2010-2017. Nairobi: Ministry of Public Health and Sanitation; 2009.

18. Ministry of Health. Kenya Annual Malaria Report 2012-2013. Nairobi: Ministry of Health; 2013

19. Munyekenye OG, Githeko AK, Zhou G, Mushinzimana E, Minakawa N, Yan G. Plasmodium falciparum spatial analysis, western Kenya highlands. Emerg Infect Dis. 2005;11:1571-7.

20. Desai MR, Dhar R, Rosen DH, Kariuki SK, Shi YP, Kager PA, Ter Kuile FO. Daily iron supplementation is more efficacious than twice weekly iron supplementation for the treatment of childhood anaemia in western Kenya. J Nutr. 2004;134:1167-74

21. Desai MR, Mei JV, Kariuki SK, Wannemuehler KA, Phillips-Howard PA, Nahlen BL, Kager PA, Vulule JM, ter Kuile FO. Randomized, controlled trial of daily iron supplementation and intermittent sulfadoxine-pyrimethamine for the treatment of mild childhood anaemia in western Kenya. J Infect Dis. 2003; 187:658-66.

22. Terlouw DJ, Desai MR, Wannemuehler KA, Kariuki SK, Pfeiffer CM, Kager PA, Shi YP, Ter Kuile FO. Relation between the response to iron supplementation and sickle cell haemoglobin phenotype in preschool children in western Kenya. Am J Clin Nutr. 2004;79:466-72.

23. Guideline on the choice of the non-inferiority margin. Pre-authorisation Evaluation of Medicines for Human Use. Document reference EMEA/CPMP/ EWP/2158/99. London, UK: European Medicines Agency; 2005. http://www. ema.europa.eu/docs/en_GB/document_library/Scientific_guideline/2009/09/ WC500003636.pdf. Accessed 30 Jan 2017.

24. World malaria report. Geneva: World Health Organization; 2010. http://www. who.int/malaria/world_malaria_report_2010/worldmalariareport2010.pdf. Accessed 30 Jan 2017. 
25. Preventive chemotherapy in human helminthiasis. Coordinated use of antihelminthic drugs in control interventions: a manual for health professionals and programme managers. Geneva: World Health Organization; 2006. http://whqlibdoc.who.int/publications/2006/ 9241547103_eng.pdf. Accessed 30 Jan 2017.

26. Tarning J, Zongo I, Some FA, Rouamba N, Parikh S, Rosenthal PJ. Population pharmacokinetics and pharmacodynamics of piperaquine in children with uncomplicated falciparum malaria. Clin Pharmacol Therap. 2012;91:497-505.

27. White NJ. Qinghaosu (artemisinin): the price of success. Science. 2008;320:330-4

28. White NJ. How antimalarial drug resistance affects post-treatment prophylaxis. Malaria J. 2008;7:9

29. D'Agostino RB, Massaro JM, Sullivan LM. Non-inferiority trials: design concepts and issues - the encounters of academic consultants in statistics. Stat Med. 2003;22:169-86.

30. Guidance for industry: non-inferiority clinical trials. Silver Spring: US Department of Health and Medical Services/Food and Drug Administration; 2010. http://www.fda.gov/downloads/drugs/ guidancecomplianceregulatoryinformation/guidances/ucm202140.pdf. Accessed 30 Jan 2017.

31. Schumi J, Wittes JT. Through the looking glass: understanding noninferiority. Trials. 2011;12:106.

32. Okebe JU, Yahav D, Shbita R, Paul M. Oral iron supplements for children in malaria-endemic areas. Cochrane Database Syst Rev. 2011;10:CD006589.

33. Programmatic guidance brief on use of micronutrient powders (MNP) for home fortification; 2011. Home Fortification Technical AG. https://www. unicef.org/nutrition/files/HFTAG_Micronutrient_Powder_Program_ Guidance_Brief.pdf. Accessed 30 Jan 2017.

34. Verhoef H, Veenemans J, Mwangi MN, Prentice AM. Safety and benefits of interventions to improve folate status in malaria-endemic areas. Brit J Haematol. (Accepted for publication).

35. Cramer JA, Mattson RH, Prevey ML, Scheyer RD, Ouellette VL. How often is medication taken as prescribed? A novel assessment technique. JAMA 1989;261:3273-377.

36. Vrijens B, Urquhart J. Patient adherence to prescribed antimicrobial drug dosing regimens. J Antimicrob Chemother. 2005;55:616-27.

37. Hallberg $L$, Rossander $L$, Skanberg AB. Phytates and the inhibitory effect of bran on iron absorption in man. Am J Clin Nutr. 1987;45:988-96.

38. Hurrell RF, Reddy MB, Juillerat MA, Cook JD. Degradation of phytic acid in cereal porridges improves iron absorption by human subjects. Am J Clin Nutr. 2003;77:1213-9.

39. Principles for the safety assessment of food additives and contaminants in food. Environmental Health Criteria 70. Geneva: World Health Organization; 1987. http://www.who.int/iris/handle/10665/37578. Accessed 30 Jan 2017.

40. Evaluation of certain food additives and contaminants. Sixty-eighth report of the Joint FAO/WHO Expert Committee on Food Additives. WHO Technical Report Series No. 947. Geneva: World Health Organization; 2007. http://apps.who.int/iris/bitstream/10665/43870/1/9789241209472_eng.pdf. Accessed 30 Jan 2017.

41. Haemoglobin concentrations for the diagnosis of anaemia and assessment of severity. Vitamin and Mineral Nutrition Information System. Document reference WHO/NMH/NHD/MNM/11.1. Geneva: World Health Organization; 2011. http:// www.who.int/vmnis/indicators/haemoglobin.pdf. Accessed 30 Jan 2017.

42. Serum ferritin concentrations for the assessment of iron status and iron deficiency in populations. Vitamin and Mineral Nutrition Information System. Document reference WHO/NMH/NHD/MNM/11.2. Geneva: World Health Organization; 2011. http://www.who.int/vmnis/indicators/serum_ ferritin.pdf. Accessed 30 Jan 2017.

43. Malaria rapid diagnostic test performance: executive summary. Results of WHO product testing of malaria RDTs: round 1 (2008). Geneva: World Health Organization; 2009. http://www.who.int/tdr/news/documents/ executive-summary-malaria-RDTs.pdf . Accessed 30 Jan 2017.

44. Abraham K, Muller C, Gruters A, Wahn U, Schweigert FJ. Minimal inflammation, acute phase response and avoidance of misclassification of vitamin A and iron status in infants-importance of a high-sensitivity C-reactive protein (CRP) assay. Int J Vitam Nutr Res. 2003;73:423-30.

45. Ayoya MA, Spiekermann-Brouwer GM, Stoltzfus RJ, Nemeth E, Habicht JP, Ganz T, Rawat R, Traoré AK, Garza C. Acid glycoprotein, hepcidin, C-reactive protein, and serum ferritin are correlated in anemic schoolchildren with Schistosoma haematobium. Am J Clin Nutr. 2010;91:1784-90.

46. Cramer JA, Mattson RH, Prevey ML, Scheyer RD, Ouellette VL. How often is medication taken as prescribed? A novel assessment technique. JAMA. 1989;261:3273-7.

47. Bland JM, Altman DG. Measurement error proportional to the mean. BMJ. 1996;313:106.

48. Suchdev PS, Namaste SM, Aaron GJ, Raiten DJ, Brown KH, Flores-Ayala R, BRINDA Working Group. Overview of the Biomarkers Reflecting Inflammation and Nutritional Determinants of Anemia (BRINDA) project. Adv Nutr. 2016;7:349-56

49. Malvy DJ, Povéda JD, Debruyne M, Montagnon B, Burtschy B, Herbert C, Cacès $P$, Houot $O$, Amédée-Manesme $O$. Laser immunonephelometry reference intervals for eight serum proteins in healthy children. Clin Chem. 1992;38:394-9.

50. Altman DG, Royston P. The cost of dichotomising continuous variables. BMJ. 2006:332:1080

51. Ragland DR. Dichotomizing continuous outcome variables: dependence of the magnitude of association and statistical power on the cutpoint. Epidemiology. 1992;3:434-40.

52. Marquart L, Butterworth A, McCarthy JS, Gatton ML. Modelling the dynamics of Plasmodium falciparum histidine-rich protein 2 in human malaria to better understand malaria rapid diagnostic test performance. Malar J. 2012;11:74.

53. Aydin-Schmidt B, Mubi M, Morris U, Petzold M, Ngasala BE, Premji Z, Björkman A, Mårtensson A. Usefulness of Plasmodium falciparum-specific rapid diagnostic tests for assessment of parasite clearance and detection of recurrent infections after artemisinin-based combination therapy. Malar J. 2013;12:349.

54. Guidelines for treatment of malaria. $3^{\text {rd }}$ ed. Geneva: World Health Organization; 2015. p. 237-45. http://apps.who.int/iris/bitstream/10665/ 162441/1/9789241549127 eng.pdf. Accessed 30 Jan 2017.

55. Zongo I, Milligan P, Compaore YD, Some AF, Greenwood B, Tarning J, Rosenthal PJ, Sutherland C, Nosten F, Ouedraogoa J-B. Randomized noninferiority trial of dihydroartemisinin-piperaquine compared with sulfadoxine-pyrimethamine plus amodiaquine for seasonal malaria chemoprevention in Burkina Faso. Antimicrob Agents Chemother. 2015:59:4387-96.

56. Wreesmann CTJ. Reasons for raising the maximum acceptable daily intake of EDTA and the benefits for iron fortification of foods for children 6-24 months of age. Matern Child Nutr. 2014;10:481-95.

57. Bouhouch RR, El-Fadeli S, Andersson M, Aboussad A, Chabaa L, Zeder C, Kippler M, Baumgartner J, Sedki A, Zimmermann MB. Effects of wheat-flour biscuits fortified with iron and EDTA, alone and in combination, on blood lead concentration, iron status, and cognition in children: a double-blind randomized controlled trial. Am J Clin Nutr. 2016:104:1318-26.

58. Verhoef $H$, West CE, Nzyuko SM, de Vogel S, van der Valk R, Wanga MA, Kuijsten A, Veenemans J, Kok FJ. Intermittent administration of iron and sulfadoxine-pyrimethamine to control anaemia in Kenyan children: a randomised controlled trial. Lancet. 2002·360:908-14.

59. Barth-Jaeggi T, Moretti D, Kvalsvig J, Holding PA, Njenga J, Mwangi A, Chhagan MK, Lacroix C, Zimmermann MB. In-home fortification with 2.5 mg iron as NaFeEDTA does not reduce anaemia but increases weight gain: a randomised controlled trial in Kenyan infants. Matern Child Nutr. 2015;11 Suppl 4:151-62.

60. Zlotkin S, Antwi KY, Schauer C, Yeung G. Use of microencapsulated iron(II) fumarate sprinkles to prevent recurrence of anaemia in infants and young children at high risk. Bull World Health Organ. 2003:81:108-11.

61. Prentice AM, Doherty CP, Abrams SA, Cox SE, Atkinson SH, Verhoef $H$, Armitage $A E$, Drakesmith $H$. Hepcidin is the major predictor of erythrocyte iron incorporation in anemic African children. Blood. 2012;119:1922-8.

62 Rothman KJ, Michels KB. The continuing unethical use of placebo controls. N Engl J Med. 1994;331:394-8.

63 Van der Graaf R, Rid A. Placebo-controlled trials, ethics of. In: Wright JD, editor. International encyclopedia of the social \& behavioral sciences, vol. 18. 2nd ed. Oxford: Elsevier; 2015. p. 164-73.

64 World Medical Association. World Medical Association Declaration of Helsinki: ethical principles for medical research involving human subjects. JAMA. 2013;310:2191-4. 
65 LeLorier J, Gregoire G, Benhaddad A, Lapierre J, Derderian F. Discrepancies between meta-analyses and subsequent large randomized, controlled trials. N Engl J Med. 1997;337:536-42.

66 Villar J, Carroli G, Belizan JM. Predictive ability of meta-analyses of randomised controlled trials. Lancet. 1995;345:772-6.

67 ICH Harmonised tripartite guideline: choice of control group and related issues in clinical trials E10. International Conference on Harmonisation of Technical Requirements for Registration of Pharmaceuticals for Human Use (ICH); 2000. http://www.ich.org/fileadmin/Public_Web_Site/ICH_Products/ Guidelines/Efficacy/E10/Step4/E10_Guideline.pdf. Accessed 30 Jan 2017.

Submit your next manuscript to BioMed Central and we will help you at every step:

- We accept pre-submission inquiries

- Our selector tool helps you to find the most relevant journal

- We provide round the clock customer support

- Convenient online submission

- Thorough peer review

- Inclusion in PubMed and all major indexing services

- Maximum visibility for your research

Submit your manuscript at www.biomedcentral.com/submit
Biomed Central 